\title{
Reflections on Wallace
}

\section{An unpublished paper has recently come to light, which shows that even at an early age, Alfred Russel Wallace was bold enough to approach the scientific establishment with his ideas.}

\section{Charles H. Smith}

The image of Alfred Russel Wallace as a self-effacing satellite to Darwin's more resolute brilliance has taken a fresh blow. An early, unpublished Wallace paper illustrates his boldness in approaching leading scientists with his ideas. In the spring of 1843 , some 15 years before he wrote to Darwin setting out his thoughts on evolution, Wallace described possible ways to improve the mirrors used in telescopes in a letter and paper sent to William Henry Fox Talbot. At that time, Talbot was a leading man of science, already famous for his invention of a successful early form of photography.

I chanced upon this paper earlier this year as the result of a Google search. Finding that an 1843 letter by "Alfred R. Wallace, surveyor" had been transcribed online as part of a project called "The Correspondence of William Henry Fox Talbot", I contacted the project's director, Larry Schaaf, and asked whether the paper mentioned in the letter still existed. It did. Even the envelope in which the letter and manuscript were originally delivered to Talbot had been preserved. The paper is reproduced on the next page.

Having been forced to leave school at 13, Wallace had been working for six years for his older brother William, as a surveyor at various locations in the west of England and South Wales. But the curators of the Fox Talbot correspondence project had not realized this young surveyor was the Wallace who is now famous as one of the founders of the theory of natural selection.

At this point Wallace had not met his future colleague Henry Walter Bates, corresponded with or met Darwin, read the anticreationist best-seller Vestiges of the Natural History of Creation (it was published the following year) or shown any real interest in the problem of the origin of species, which would lead to his most famous work.

Schaaf is a renowned authority on the early history of photography. He says the ideas Wallace expressed in his paper addressed challenges in optical engineering that may have been too difficult technologically to implement at the time.

According to Schaaf, Wallace was basically saying that gravity pulls a pool of mercury into a near-perfect plane and that by electroplating another metal on to the layer of mercury, one could form a perfectly flat mirror.

Later on in the paper, Wallace discusses curved mirrors. Schaaf says that at the time, these were cast in alloys and then ground by hand to the best trial and error curvature possible. They tarnished quickly and had to be constantly repolished, without changing the curvature. "Astronomers spent as much time doing that as they did looking at the heavens," explains Schaaf. "So it was a real problem and Wallace and Talbot were exploring different but related approaches to solving it." Talbot was obviously interested enough to keep the letter and paper, although it is not known whether he ever sent Wallace a reply.

But this may not be the end of the story. A technology known as liquid spinning mirror telescopy' is also based on the use of mercury, and is currently being developed at several locations around the world. According to Paul Hickson, the leader of one group that's developing it at the University of British Columbia in Vancouver, the first mention of the liquid-mirror technique can be found in a published letter by the astronomer Ernesto Capocci.

Capocci was a colleague of and corresponded with the noted optician and microscopist Giovanni Battista Amici, who in turn had received Talbot in Italy as a guest several times since the early 1820s and exchanged at least 24 letters with him. In fact, Amici visited Talbot while in London in 1844 on optics-related business, and less than three years later, his son Vincenzo, a mathematician, published a paper entitled "Considerazioni sulla teoria del moto dei liquidi" (Considerations on the theory of motion in liquids). So it is possible that some of Wallace's ideas found their way into published work after all.

Wallace was just 20 years old when he wrote the paper on mirrors, and it is, by seven years, his earliest extended writing on a technical subject that we know of. His first published paper, a short characterization of the Amazonian umbrella bird, appeared in 1850 .

It is interesting that the young and selfeducated Wallace had enough confidence in his idea to set it before the leading English thinker of the time on such matters. Fifteen years later he would do the same with Darwin. In his autobiography, Wallace describes how he never shied away from debate once he felt he had firmly grasped the basic elements of a question. When it came to serious discussion, mere weight of reputation meant little to him.

His correspondence with Talbot also helps us appreciate certain threads in Wallace's intellectual life that are often

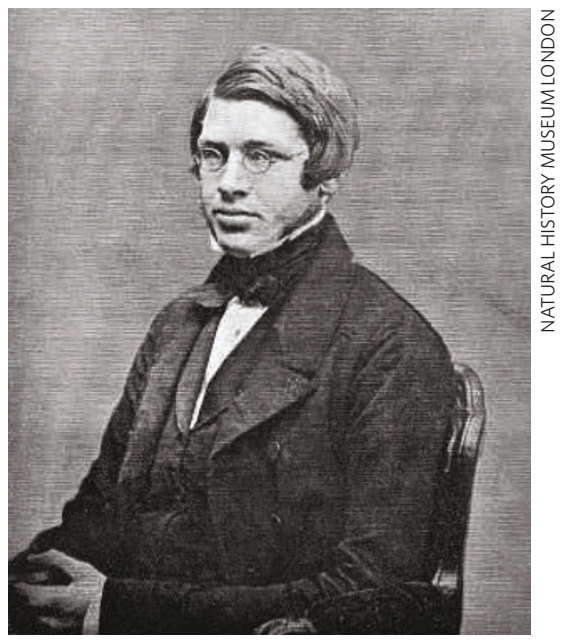

Intrepid: Alfred Russel Wallace did not shy away from debate with leading scientists.

peripheralized in discussions of his contributions to evolutionary biology and biogeography. Remarks in his autobiography and several secondary sources suggest that he had mastered basic principles of optics, surveying, geodesy and astronomy by the age of 18 or 20 .

This 'quickness' would later support his entry into a variety of debates. And Wallace's strong interest in optics and photography would inform several of his more unusual investigations, such as his interpretation of the canal-like structures appearing on contemporary photographs of Mars, over which he argued with the astronomer Percival Lowell.

My discovery of this paper underlines the increasing value of the Internet as a means of identifying archival sources relevant to ongoing research. Were it not for Schaaf's efforts in making the correspondence of Fox Talbot electronically accessible, this particular item might have remained undiscovered for another 163 years.

Charles H. Smith is Professor of Library

Public Services and Science Librarian at Western Kentucky University, Bowling Green, Kentucky, USA.

FURTHER READING

Fichman, M. An Elusive Victorian: The Evolution of Alfred Russel Wallace (Univ. Chicago Press, Chicago, 2003).

The Correspondence of William Henry Fox Talbot http://foxtalbot.dmu.ac.uk/

The Alfred Russel Wallace Page http://www.wku. edu/ smithch/index1.htm

The British Library has recently obtained the original Wallace letter and paper; transcriptions of each may be viewed online at http://foxtalbot. dmu.ac.uk/letters/transcriptDocnum. php?docnum $=4807$ 
On a probable means of procuring plane and curved Specula of Great size, with a few remarks on fixed telescopes. by A. R. Wallace.

On considering the means of obtaining in the first place a perfect plane Reflecting surface, it appears that nature in certain instances produces one much superior to any thing the art of man can form. The surface of quiescent fluid mercury is perhaps the best of these and all we want is to fix it immoveably or obtain a perfect copy of it. There are many difficulties in the way of the latter but it is not unlikely that the Electrotype offers a means of overcoming them, and producing in solid metal a truly plane polished mirror. There appears no reason why the operation should not be successful; the vessel containing the metallic solution might have a stratum of mercury at the bottom and the moment the connection was made by the wire touching the mercury the operation would commence, an almost infinitely thin pellicle being first deposited the surface must be accurately copied, and in fact it has been shewn that a surface equally polished with the copy is produced. The difficulty of keeping the vessel perfectly free from vibration might doubtless be got over; the only question then remaining is a Chemical one: what metal can be deposited that would not in any degree combine with the mercury? Neither Gold nor Copper would do, perhaps Iron or Antimony might do better, but that which would answer must be determined by experiment. The writer much regrets that the circumstances in which he is placed have not permitted him either the time or expense necessary to ascertain these points. Should the metal deposited not reflect sufficient light he conceives a great advantage would still be obtained over performing the whole operation by hand as a thin pellicle of Gold or other metal might be deposited over it and that if necessary polished. Even should all efforts to deposit a metal on Mercury so as to produce a polished surface, fail, the principle might still perhaps be applied by obtaining some fluid which would consolidate with a polished surface. it might then be metallized in the manner usually employed for Electrotype operations and though perhaps a highly polished surface might not be thus obtained still it would be a great assistance to have a true homogenous plane surface requiring nothing but the last polish to render it fit for use. Trusting however that whatever difficulties may be presented will be overcome he will proceed to point out the advantages that may result from its success. We should then have a perfect plane mirror of any size to reflect the rays to the concave speculum and thus one great difficulty of using telescopes of large size fixed, would be got over.

Having however obtained a plane mirror it appears not impossible that we may also produce the concave one without going through the tedious, uncertain, and expensive operations of grinding and polishing. It is evident that a plane mirror produced as before described would be both perfectly uniform in its thickness and perfectly homogenous in its structure. The writer of this was much interested some time ago with Mr. Nasmyth's method of producing concave reflectors by extracting the air from a chamber behind a circular plate of glass and allowing the pressure of the atmosphere to produce the required curvature. He has not been able to learn why this has not succeeded or been brought into operation, but supposes it must be from the difficulty of procuring plates of glass sufficiently uniform in thickness, homogenous in structure, and truly plane in both surfaces without all of which it is evident a uniform curve would not be produced. Mr. Nasmyth conceives that the curve would be between a catenary and circle, but does it not appear more likely that it would be truly parabolic, the pressure of the atmosphere being similar to an infinite number of perpendicular pressures. If so it appears difficult to imagine how a perfectly plane homogenous body of uniform thickness, placed under such a pressure could take any other than a true parabolic form. If it did there would be a curved mirror formed superior probably to any yet made. It also seems probable that the metal after being exposed to the pressure, would on its being removed retain a portion of its curvature sufficient for a long focus and thus obviate the inconvenience of having to keep the atmospheric pressure perfectly uniform in order to preserve the same focal length.

In fixing a telescope for the purpose of using a moveable plane Speculum to reflect the objects to the curved one, it appears evident that that position must be best which requires the plane mirror to be of the least possible size. To effect this the tube must be directed to a point midway between the Pole and a few degrees above the Southern Horizon or in this Country about $20^{\circ}$ South of the Zenith, (on the supposition that it is not required to view objects more than a few degrees below the Pole) the Great curved Speculum being at the top and the plane mirror and observer at the bottom; In this situation the plane mirror need be only $1 / 7$ th larger than the Speculum to reflect rays to the whole of its surface from objects least favourably situated, while if directed toward the Pole with the Speculum at the top the plane mirror must be nearly twice the diameter and with the speculum at bottom, no dimensions of plane mirror would reflect light from objects near the Pole to the whole surface of the Speculum.

The plane mirror might be made to keep an object in the field of view with great facility in whatever direction the telescope were placed, by fixing it in the manner of an equatorial so as to be elevated to the proper angle and moved round on a polar axis.

The writer has thus concisely expressed his ideas on these subjects in the hope that if they are at all novel, some one may be found to put them to the test of experiment and ascertain whether these methods of increasing the power of the Telescope are capable of practical application. 